\title{
Minimum skills required by children to complete health- related quality of life instruments for asthma: comparison of measurement properties
}

\author{
E.F. Juniper*, G.H. Guyatt*+, D.H. Feeny**, L.E. Griffith*, P.J. Ferrie*
}

\begin{abstract}
Minimum skills required by children to complete health-related quality of life instruments for asthma: comparison of measurement properties. E.F. Juniper, G.H. Guyatt, D.H. Feeny, L.E. Griffith, P.J. Ferrie. CERS Journals Ltd 1997.

ABSTRACT: To gain a complete picture of a child's health-status, measurement of health-related quality of life (HRQL) is necessary. Since parents do not accurately perceive children's HRQL, information must be obtained from the children themselves. The aim of this study was to determine the minimum age and reading skills required by children to complete competently the Paediatric Asthma Quality of Life Questionnaire (PAQLQ), the Health Utilities Index (HUI), the Feeling Thermometer and the Standard Gamble, and to evaluate the validity of each for measuring HRQL in children with asthma.

Fifty two children (age 7-17 yrs) with symptomatic asthma participated in a 9 week single cohort study with HRQL and clinical asthma control assessed every 4 weeks.

All children provided very reliable data for the PAQLQ and the HUI but they needed $\geq$ grade 6 reading skills to complete the Standard Gamble and $\geq$ grade 2 skills for the Feeling Thermometer. In those children who were able to provide reliable data, the PAQLQ had the best discriminative and evaluative measurement properties, followed closely by the Feeling Thermometer. Measurement properties in the Standard Gamble were weaker and although the HUI was very reliable it was not actually measuring asthma-specific HRQL.

The Paediatric Asthma Quality of Life Questionnaire may be used with confidence in clinical studies and practice to provide a profile of children's day-to-day experiences. In those children with adequate skills to complete the test reliably, the Feeling Thermometer provides a good estimate of the value that children place on their asthma health status.

Eur Respir J 1997; 10: 2285-2294.
\end{abstract}

Depts of *Clinical Epidemiology and Biostatistics, and + Medicine, and + Centre for Health Economics and Policy Analysis, McMaster University, Hamilton, Ontario, Canada

Correspondence: E.F. Juniper

Dept of Clinical Epidemiology and Biostatistics

McMaster University Faculty of Health Sciences

1200 Main Street West

Hamilton

Ontario

Canada L8N 3 Z5.

Keywords: Asthma

paediatrics

quality of life

Received: April 291996

Accepted after revision July 101997

Supported through a grant from Fisons Canada
Many paediatricians now recognize the importance of incorporating an assessment of health-related quality of life (HRQL) into their clinical studies. Conventional clinical measures usually provide valuable information about the status of the affected organ system but they rarely capture the functional impairments (physical, emotional and social) that are important to the patients in their everyday lives. If one is to obtain a complete picture of a child's health status, one has to measure both the conventional clinical indices and the child's HRQL.

Parents do not accurately perceive their children's HRQL [1]. Therefore, we are dependent on obtaining the information directly from the child. Different types of HRQL instruments require different levels of understanding, reading skills and reasoning, but to date there is minimal information to help investigators and clinicians decide whether the children they intend to study can provide meaningful data from the instruments they would like to use. Both generic [2, 3] and disease-specific paediatric HRQL questionnaires [4, 5] are available for use in children with asthma and, in the future, with the growing importance of health economics, we will see an increased use of preference measures and utilities. Therefore, we felt that it was timely to determine the age and skills required by children for reliable completion of these different types of instruments.

We selected four HRQL instruments to represent the spectrum of instruments likely to be used in the future. They represent the different types of instruments (generic and disease-specific questionnaires and utilities) and each requires very different types and levels of skills: 1) the Paediatric Asthma Quality of Life Questionnaire (PAQLQ) [4] is an interviewer-administered disease-specific questionnaire with responses given, using a sevenpoint scale; 2) the Health Utilities Index (HUI) Mark 2 and Mark 3 system [2,3] is a self-administered generic questionnaire which has predominantly dichotomous responses; 3) the Feeling Thermometer [6] is a conceptually simple preference-measurement instrument; 4) the Standard Gamble [6] is a utility instrument that requires quite sophisticated conceptual skills.

Our objectives in conducting this study were entirely practical. We wanted to know whether these published HRQL instruments are capable of measuring 
HRQL in children with asthma and, if so, what are the minimum skills required for reliable completion. It was not our intent to explore the theories of developmental understanding in children. These are certainly important (e.g. children's perception of death for the Feeling Thermometer and the Standard Gamble) but such a discussion would of necessity be lengthy and detract from our practical objective. In addition, there are numerous excellent and comprehensive discussions on these issues to be found in the child development literature.

In this study, we first estimated the minimum age, school grade and reading skills needed to complete each of these instruments reliably and then, in children who were able to provide reliable data, we have examined the validity of these instruments for measuring asthmaspecific quality of life in children.

\section{Methods}

\section{Patients}

Using notices placed in the local media and paediatric asthma clinics, and through parents who had taken part in our adult asthma studies, we recruited 52 children (aged 7-17 yrs) with asthma, as defined by the American Thoracic Society guidelines. Patients experiencing asthma symptoms during the week prior to enrollment with a score of less than 6.5 on the symptom domain of the PAQLQ $(7.0=$ no impairment and $1.0=$ severe impairment) were included. We excluded children if they: had illnesses other than asthma that affected quality of life; had recurrent chest infection requiring treatment with antibiotics; were unable to perform reliable peak expiratory flow rates at home; or had required oral steroids during the previous 2 weeks. Each child was accompanied to the clinic on each visit by the primary caregiver, usually a parent. Children over the age of $12 \mathrm{yrs}$ and all caregivers signed an informed consent that had been approved by the McMaster University Faculty of Health Sciences Ethics Committee.

\section{Study design}

Children were seen in the clinic at enrollment and after 1, 5 and 9 weeks. At weeks 1, 5 and 9, a trained interviewer administered the PAQLQ, the HUI, the Feeling Thermometer and the Standard Gamble. All instruments were administered with the caregiver absent. Questions in the PAQLQ and the HUI were never interpreted, paraphrased or explained for the children. If a child appeared to have difficulty with a question, it was repeated verbatim.

At each visit, we measured spirometry before and after a bronchodilator. At the first visit, we tested children for their word recognition and reading comprehension skills using the Brigance Comprehensive Inventory of Basic Skills [7]. At weeks 5 and 9, the children completed a global rating of change questionnaire that asked whether there had been any change in their asthma since the previous visit. For 1 week before each follow-up visit, the children completed a daily symptom and med- ication diary and made morning peak flow measurements. At the clinic visit, a clinical asthma control score was calculated [4]; this is a composite of asthma symptoms (awoken by symptoms at night, waking in the morning with symptoms, sputum, limitation of daily activities), spirometry (forced expiratory volume in one second (FEV1) $<70 \%$ of predicted value) and bronchodilator use ( $\beta$-agonist use more than four times per day). A point is scored for each of the six items present $(0=$ good control, $6=$ very poor control).

At weeks 1, 5 and 9, the caregiver completed the Paediatric Asthma Caregiver's Quality of Life Questionnaire [8] and the Impact-on-Family Scale [9]. At weeks 5 and 9 , caregivers completed a global rating of change questionnaire [10] on their child's asthma symptoms.

\section{Quality of life instruments}

Paediatric Asthma Quality of Life Questionnaire [4]. This instrument was developed to measure asthma-specific quality of life in children aged 7-17 yrs. The 23 items in the questionnaire cover those problems associated with asthma which have been identified by children with asthma as being important and bothersome to them in their day-to-day lives [11]. The words used in the questionnaire are those that the children themselves use to describe their problems. The items are in three domains: symptoms $(\mathrm{n}=10)$; emotional function $(\mathrm{n}=8)$; and activity limitation $(n=5)$. Three of the activity items are "individualized" and identified by the child at the first visit. The questionnaire is available in both interviewer and self-administered formats. In this study, we used the interviewer-administered version. The response options of the PAQLQ are on a seven-point scale where 1 indicates maximum impairment and 7 indicates no impairment. Patients are provided with a card on which the responses are listed. A verbal descriptor follows each number, e.g. 1=extremely bothered, $2=$ very bothered, $3=$ quite bothered ... 7=not bothered. The interviewer reads the question and the child gives the response, from the card, that best describes his or her experiences during the previous week. The questionnaire takes approximately $10-15 \mathrm{~min}$ to complete at the first visit and 7 min at follow-up. Prior to use in English and all subsequent languages, the questionnaire was pretested in children to ensure that even the youngest understood each of the questions and the response options. For overall quality of life and for each of the domains, the Minimal Important Difference (MID) has been determined to be a change in score of 0.5 [4]. The MID has been defined as "the smallest difference in score in the domain of interest which patients perceive as beneficial and would mandate, in the absences of troublesome sideeffects or excessive cost, a change in the patient's management" [10].

Health Utilities Index [2, 3]. This is a generic multiattribute questionnaire used to assess health status in the HUI2 and HUI3 systems [2, 3]. There are 10 attributes (vision, hearing, speech, mobility, dexterity, self-care, feelings, memory, thinking and pain and discomfort). The impairment experienced in the first five attributes is ascertained using Guttman-style questions. For instance, 
in the vision attribute, the first question asks "Are you usually able to see well enough to read ordinary newsprint without glasses or contact lenses?". If the response is "yes", the respondent goes on to the next attribute. If the response is "no", the patient continues to the questions which progressively ascertain the level of vision impairment. For the final five attributes, response options range from three-point to five-point. The time frame is not specified. To calculate the overall score for each patient, we used the weightings that had been derived previously from a multiplicative, multi-attribute utility function based on the preferences of a random sample of the general population [3, 4]. In this study, if children had insufficient reading skills to understand the questions or instructions, the interviewer administered the questionnaire. The questionnaire takes approximately 5-7 min to complete.

The Feeling Thermometer [6]. This preference-measurement instrument explores how patients feel about their own health state and the value they place upon it. The instrument looks like a thermometer with clearly defined end points: $0=$ least preferred health state (death), and $100=$ most preferred health state (perfect health). In this study, patients first read aloud (if necessary with the interviewer's help) a description of three hypothetical "marker" health states, derived from the PAQLQ:

Mild asthma: "You have asthma but it hardly bothers you at all. Occasionally, you wheeze and are a little short of breath. Your asthma does not limit you in any sports or games. You have no problems at school. Your asthma does not bother you at night. Your asthma is never frightening."

Moderate asthma: "You have asthma and it bothers you quite a bit. You wheeze quite often and get short of breath. Your asthma limits you in many things you like doing, such as sports and games. Your asthma sometimes wakes you up at night. You get frustrated by your asthma and sometimes an attack is a bit frightening."

Severe asthma: "You have asthma and it is really bothersome. You feel wheezy and it is difficult to breath a lot of the time. You can't join in any sports or games. At night it is difficult to sleep because of your asthma. Quite often you get bad asthma attacks and these are very frightening."

We asked the children to place a marker on the thermometer to reflect their feelings about each of the three health states. We then asked the patients to think about how their own asthma had been during the previous week and to place a marker on the thermometer to reflect their feelings about this. Only this final score was used in the analysis. The instrument takes approximately 12 min to complete at the first visit and $7 \mathrm{~min}$ at followup.

The Standard Gamble [6]. This utility instrument also measures the value that patients place on their own health state. A full description of the protocol for eliciting values may be found elsewhere [6]. Conceptually, patients are asked to think about a health state and then to consider whether they would prefer to remain in that health state or take a chance with a new (imaginary) treatment. They are told that the new treatment has the ability to return them to perfect health immediately with no side- effects but may cause instant death. In other words, patients are asked whether they would prefer the certainty of remaining in their current health state or whether they would prefer to take a gamble with the treatment which will result in either perfect health or death. Initially, if they take the treatment (gamble), the probability of perfect health is set at $100 \%$ with absolutely no chance of death. All those who understand the concept choose to take the new treatment (the gamble) rather than stay in their present health state. In theory, the probability of perfect health is then gradually reduced (and the chance of death increased) until the patient decides to remain in his/her own current health state rather than take the new treatment (the gamble). In practice, the probability of perfect health (p) and death (1-p) is varied until a point of indifference is found. The indifference probability represents the value that the patient places on his/her health state. In this study, we first administered the Standard Gamble with each of the three hypothetical asthma states used for the Feeling Thermometer and then we asked children about their own asthma during the previous week. Only the score for the child's own health state was used in the analysis. The instrument takes approximately $30 \mathrm{~min}$ to administer at the first visit and $20 \mathrm{~min}$ at follow-up. Before administering the Standard Gamble to a child, we explained the entire procedure to the parent. None declined to have it administered to their children.

\section{Word recognition and reading comprehension}

We used the Brigance Comprehensive Inventory of Basic Skills [7] to obtain each child's Word Recognition Grade Placement and Reading Vocabulary Comprehension Grade Placement. For the former, the child is asked to read aloud lists of words which progressively become more difficult. A child must correctly pronounce five of 10 words in a category to pass to the next level. In the comprehension test, the child is shown three groups of five words. In each group, one word does not belong. The child is asked to identify the three incorrect words (one from each group) and must get two right to pass on to the next and more difficult level. The Brigance testing system originated in the USA and the results of the tests are based on the USA school grading system.

\section{Other questionnaires used in the study}

Paediatric Asthma Caregiver's Quality of Life Questionnaire [8]. This self-administered questionnaire assesses the quality of life of parents of children with asthma. It has four items on activity limitations and nine on emotional function. The questionnaire presents responses to each item on a seven-point scale and caregivers recall impairments experienced during the previous week. The instrument has good reliability, responsiveness and validity [8].

Impact-on-Family Scale [9]. This 24 item quality of life instrument evaluates the impact of a child's illness on 
family function. It has four domains: financial $(n=4)$; family/social $(n=9)$; personal strain $(n=6)$; and mastery $(n=5)$, with responses to each item presented on a fourpoint Likert scale (strongly agree to strongly disagree). Internal consistency (Cronbach's alpha) for overall impact and for each domain ranges $0.60-0.88$.

Global rating of change questionnaires [10]. These questionnaires ask about changes in health status and quality of life since the previous clinic visit. At each follow-up visit, we asked both children and caregivers whether there had been any change in the child's asthma since their previous clinic visit, scoring responses on a 15point scale from -7 (a very great deal worse) to 0 (no change) to +7 (a very great deal better).

\section{Classifying patients as changed or unchanged}

Each patient had two study periods (2-5 weeks and 6-9 weeks). For each period, we categorized patients either as having stayed the same (Group A) or changed (Group B) using three independent methods: 1) if patients scored $-1,0$ or +1 on the symptom global rating of change questionnaire, they were considered to have stayed the same and if they scored between -7 and -2 or between +2 and +7 they were considered to have changed; 2 ) if the caregiver scored $-1,0$ or +1 on their perception of whether the child's symptoms had changed, the child was considered stable, for all other scores the child was considered to have changed; 3) using only clinical data (asthma control score, steroid and beta-agonist use, peak flow rates, spirometry and clinical comments in the patient's chart) and blinded to the HRQL data, one of the investigators (EFJ), at the time of each clinic visit, classified patients as unchanged or changed. Agreement between the methods was examined using a weighted kappa statistic.

\section{Testing competence}

We reasoned that if children fully understood the instruments, those with stable asthma (Group A) would provide data that was consistent (good reproducibility/ reliability) and responses would be accurate (good crosssectional validity). For the estimate of reproducibility, if a child contributed more than one pair of observations to Group A, our statistician (LEG) used a random number generator directly on the database to select one of the two pairs of observations for the estimate. First, we calculated the relationship between the between-subject and the total variance to obtain an intra-class correlation coefficient (ICC). If reliability appeared poor (low ICC), we plotted the within-subject standard deviation against age, school grade and reading and comprehension grade to estimate the minimum level of each that would yield reproducible data. Regression analysis was used to determine whether the estimates of reliability above and below chosen cut-points were significantly different. Since these were post hoc analyses, we have lowered the conventional level of statistical significance to $\mathrm{p}<0.01$. For the method of determining cross-sectional validity, see Validity below.

\section{Testing the measurement properties}

For discriminative use (cross-sectional surveys), instruments need to have good reliability and cross-sectional construct validity, and for evaluative use (clinical trials), instruments need to have good responsiveness and longitudinal construct validity [12].

Reliability and responsiveness. We estimated reliability, as described above, by calculating an ICC using data from children whose asthma remained stable between consecutive visits (Group A). We estimated responsiveness in three ways. First, we assessed the ability of the instruments to detect within-subject change in patients who changed (Group B) using paired t-tests. Second, we examined the ability of the instruments to distinguish between Groups A and B in terms of change in HRQL over a 4 week period using unpaired t-tests. For both estimations, symmetry of the data from those who improved and those who deteriorated justified our changing the sign in those who deteriorated. Third, we calculated the responsiveness index $(\Delta / \Delta \mathrm{SD})$ [13]. Differences in the responsiveness index between instruments were tested using paired t-tests. Some patients experienced a change in their quality of life during both study periods and therefore contributed two observations to Group B. To ensure that this did not result in an overestimate of the precision of responsiveness, we inflated the variance to take into account within-subject correlations by the quantity $1+(n-1) \rho$ where $\rho$ is the ICC of the change scores and $n=2$ (the number of observations per subject).

Validity. In addressing validity, we could have asked either whether the instruments were valid for measuring asthma-specific HRQL or whether they were valid for measuring HRQL in general. We chose the former and thus asked children completing the Feeling Thermometer and the Standard Gamble to tell us about impairments specifically related to their asthma.

Before analysing the data, four investigators (EFJ, GHG, DHF, LEG) together made predictions about the degree of correlation we should expect to find between the four instruments being tested and other indices of clinical asthma severity and quality of life if indeed the four instruments were measuring asthma-specific HRQL (a priori predictions). We evaluated the cross-sectional construct validity of the four instruments using only data from the first clinic visit. We calculated the correlations between each of the four instruments and the other indices of clinical asthma severity and HRQL. We then examined how closely these actual correlations matched our a priori predictions. Longitudinal construct validity was evaluated in a similar manner except that the correlations were between changes in scores between consecutive visits.

\section{Results}

All 52 patients finished the study and provided complete data sets. Their demographic data and baseline HRQL scores are shown in table 1. Patients represented 
Table 1. - Patient characteristics and health-related quality of life at enrollment

\begin{tabular}{lrc}
\hline Patient characteristics & & \\
Patients n & 52 & \\
Gender F/M & $22 / 30$ & \\
Age yrs & $12.0 \pm 3.1$ & $(7-17)$ \\
FEV1 \% pred & $85 \pm 16.6$ & \\
Medications n & 2 & \\
None & 15 & \\
Bronchodilators alone & 31 & \\
Inhaled steroids and bronchodilators & 4 & \\
Cromoglycate alone & 44 & \\
History of atopy* n & & \\
Health-related quality of life at enrollment & \\
Paediatric Asthma Quality of Life & & \\
Overall & $5.19 \pm 0.95$ & $(2.96-6.67)$ \\
Symptoms & $5.09 \pm 1.08$ & $(2.30-6.60)$ \\
Activities & $4.56 \pm 1.16$ & $(2.00-6.67)$ \\
Emotions & $5.72 \pm 0.90$ & $(3.63-7.00)$ \\
Health Utilities Index & $0.89 \pm 0.09$ & $(0.67-1.00)$ \\
Feeling Thermometer & $66.3 \pm 14.8$ & $(30-98)$ \\
Standard Gamble (n=40) & $0.82 \pm 0.15$ & $(0.45-1.00)$ \\
\hline
\end{tabular}

Values are mean \pm SD with range in parenthesis, apart from patient number, gender, medications and history of atopy which are given in absolute numbers of patients. *: exacerbation of asthma symptoms on exposure to specific allergens. FEV1: forced expiratory volume in one second; $\%$ pred: percentage of predicted value.

a wide range of urban/rural and socioeconomic backgrounds. The majority were Caucasian.

When categorizing whether patients stay the same (Group A) or change (Group B) during each time interval, we usually use the patients' own global rating of change [14]. Although the overall kappa $(\kappa=0.71)$ suggested that the children perceived the change in their health status well, in the youngest age group this perception was poor $(7-10$ yrs: $\kappa=0.35)$. We have shown subsequently that parents have a very poor perception of change in their child's asthma status [1] and, therefore, it would have been inappropriate to use the parent's global ratings. Good concordance between the older (11-17 yrs) children's global rating and the clinical rating $(\kappa=0.77)$ suggested that the optimal and most consistent approach would be to use the clinical rating.

\section{Understanding of the instruments and reliability of com- pletion}

Paediatric Asthma Quality of Life Questionnaire. The children had little difficulty understanding the questions, the response options or their task in answering the questions. The wording of each item was not expected to be a concern since children with asthma had chosen them and the conceptual understanding of each question had been carefully evaluated during the pretest [4]. However, we were particularly interested in whether the children would experience any difficulty understanding the concept of the seven-point scale. Every child gave all responses unaided and good reliability and validity data (see below) provided additional confidence that even the youngest understood and used the response options well. None of the children had difficulty selecting appropriate activities for the individualized section of the questionnaire. The only notable problem with the PAQLQ was the time specification in younger children. Some of these children had difficulty with the concept of "during the last week". We dealt with this problem by identifying an event that had occurred a week ago and framing the questions in relation to this event.

Thirty seven patients contributed 57 sets of observations to the "stayed the same" category (Group A). When one randomly selected observation per patient contributed to the estimation of reliability, the within-subject standard deviation was 0.17 with an ICC of 0.95 (table 2). This was consistent through each of the domains (ICC: $0.84-0.93$ ) [4], and for each age group (7-10 yrs: ICC $=0.89 ; 11-14$ yrs: $\mathrm{ICC}=0.96 ; 15-17$ yrs: $\mathrm{ICC}=0.87)$. These results provided strong evidence that all children aged 7-17 yrs can complete the PAQLQ consistently. Good cross-sectional validity provided evidence of accuracy in these patients (table 3 ). Therefore, it appears that all children aged 7-17 yrs can complete the questionnaire with competence.

Health Utilities Index. Most children completed this self-administered questionnaire unassisted. The younger ones and those with limited reading skills required help which was adjusted according to the individual child's needs. In those with inadequate reading skills, the interviewer read aloud all the questions and the response options. In older children, she read aloud only those words that the child could not read.

In the 37 patients in Group A, the within-subject standard deviation was 0.02 and the ICC of 0.93 , strongly suggesting that over the age of $7 \mathrm{yrs}$, all children can complete the questionnaire consistently. Cross-sectional validity was poor (table 3 ) and therefore it is impossible to determine from these data whether the consistency was accompanied by accuracy.

Feeling Thermometer. When we included all 37 children in the analysis, the within-subject standard deviation was 10.63 and the ICC was 0.56. The low ICC

Table 2. - Reliability of scores in patients with stable asthma (Group A)

\begin{tabular}{lcccc}
\hline Instrument & Subjects & $\begin{array}{c}\text { Within- } \\
\text { subject } \\
\text { SD }\end{array}$ & $\begin{array}{c}\text { Between- } \\
\text { subject } \\
\text { SD }\end{array}$ & ICC \\
& $\mathrm{n}$ & & & \\
\hline PAQLQ & & & & \\
$\quad$ Overall & 37 & 0.17 & 0.73 & 0.95 \\
Symptoms & 37 & 0.22 & 0.84 & 0.93 \\
Activities & 37 & 0.42 & 0.96 & 0.84 \\
Emotions & 37 & 0.23 & 0.64 & 0.89 \\
HUI & 37 & 0.02 & 0.08 & 0.93 \\
Feeling Thermometer & & & & \\
$\quad$ All patients & 37 & 10.63 & 12.02 & 0.56 \\
Age $\geq 8$ yrs & 33 & 7.71 & 12.15 & 0.71 \\
School Grade $\geq 3$ & 33 & 7.71 & 12.12 & 0.71 \\
Word Recognition $\geq 2$ & 34 & 7.72 & 12.07 & 0.71 \\
Comprehension $\geq 2$ & 34 & 7.72 & 12.07 & 0.71 \\
Standard Gamble & & & & \\
$\quad$ All patients & 29 & 0.15 & 0.09 & 0.24 \\
Age $\geq 12$ yrs & 12 & 0.10 & 0.12 & 0.55 \\
School Grade $\geq 6$ & 18 & 0.08 & 0.13 & 0.74 \\
Word Recognition $\geq 6$ & 19 & 0.08 & 0.12 & 0.70 \\
Comprehension $\geq 6$ & 16 & 0.08 & 0.13 & 0.70 \\
\hline IC : intrass corclation & & &
\end{tabular}

ICC: intraclass correlation coefficient; PAQLQ: Paediatric Asthma Quality of Life Questionnaire; HUI: Health Utilities Index. 
Table 3. - Cross-sectional construct validity+

\begin{tabular}{|c|c|c|c|c|c|c|c|c|}
\hline \multirow[b]{2}{*}{ Instrument } & \multirow[b]{2}{*}{$\begin{array}{c}\text { Patients } \\
n\end{array}$} & \multicolumn{4}{|c|}{ Clinical asthma } & \multicolumn{3}{|c|}{ Quality of life } \\
\hline & & $\begin{array}{l}\text { Asthma } \\
\text { control }\end{array}$ & $\begin{array}{l}\text { FEV1 } \\
\% \text { pred } \\
\text { (Pre-bd) }\end{array}$ & $\begin{array}{l}\text { Peak flow } \\
\text { rates }\end{array}$ & $\begin{array}{c}\beta \text {-agonist } \\
\text { use }\end{array}$ & $\begin{array}{c}\text { PAQLQ } \\
\text { Overall }\end{array}$ & $\begin{array}{l}\text { PAQLQ } \\
\text { Overall }\end{array}$ & $\begin{array}{l}\text { Impact-on- } \\
\text { family }\end{array}$ \\
\hline A priori prediction & & $0.35-0.50$ & $<0.20$ & $<0.20$ & $0.20-0.35$ & $>0.50$ & $0.20-0.35$ & $0.20-0.35$ \\
\hline PAQLQ - Overall & 52 & 0.58 & 0.07 & 0.30 & 0.47 & NA & 0.10 & 0.004 \\
\hline HUI & 52 & 0.23 & 0.04 & -0.06 & 0.09 & 0.36 & 0.14 & 0.14 \\
\hline \multicolumn{9}{|l|}{ Feeling Thermometer } \\
\hline All patients & 52 & 0.32 & 0.05 & 0.17 & 0.27 & 0.46 & 0.21 & 0.21 \\
\hline Age $\geq 8$ yrs & 47 & 0.36 & 0.11 & 0.19 & 0.30 & 0.49 & 0.34 & 0.22 \\
\hline School Grade $\geq 3$ & 46 & 0.44 & 0.12 & 0.13 & 0.35 & 0.57 & 0.33 & 0.27 \\
\hline Word Recognition $\geq 2$ & 49 & 0.41 & 0.11 & 0.09 & 0.26 & 0.55 & 0.26 & 0.24 \\
\hline Comprehension $\geq 2$ & 49 & 0.41 & 0.11 & 0.09 & 0.26 & 0.55 & 0.26 & 0.24 \\
\hline \multicolumn{9}{|l|}{ Standard Gamble } \\
\hline Age $\geq 12$ yrs & 25 & 0.12 & -0.03 & 0.13 & 0.22 & 0.12 & -0.08 & -0.10 \\
\hline School Grade $\geq 6$ & 21 & 0.18 & 0.00 & 0.27 & 0.19 & 0.08 & 0.15 & 0.25 \\
\hline Word Recognition $\geq 6$ & 20 & 0.28 & 0.11 & 0.36 & 0.38 & 0.16 & 0.29 & 0.39 \\
\hline Comprehension $\geq 6$ & 12 & 0.22 & 0.16 & 0.56 & 0.24 & 0.28 & 0.34 & 0.55 \\
\hline
\end{tabular}

+: Pearson correlation coefficient. NA: not applicable. For further definitions, see tables 1 and 2.

suggested that some children may have experienced difficulty understanding the instrument or their task. Figure 1 shows that there was a decrease in the within-subject standard deviation in children aged 8 yrs or older, those in school grade 3 or higher and those with at least grade 2 word recognition and comprehension skills. Using all these cut-points tended to result in improved reliability (table 4). Good cross-sectional valid-
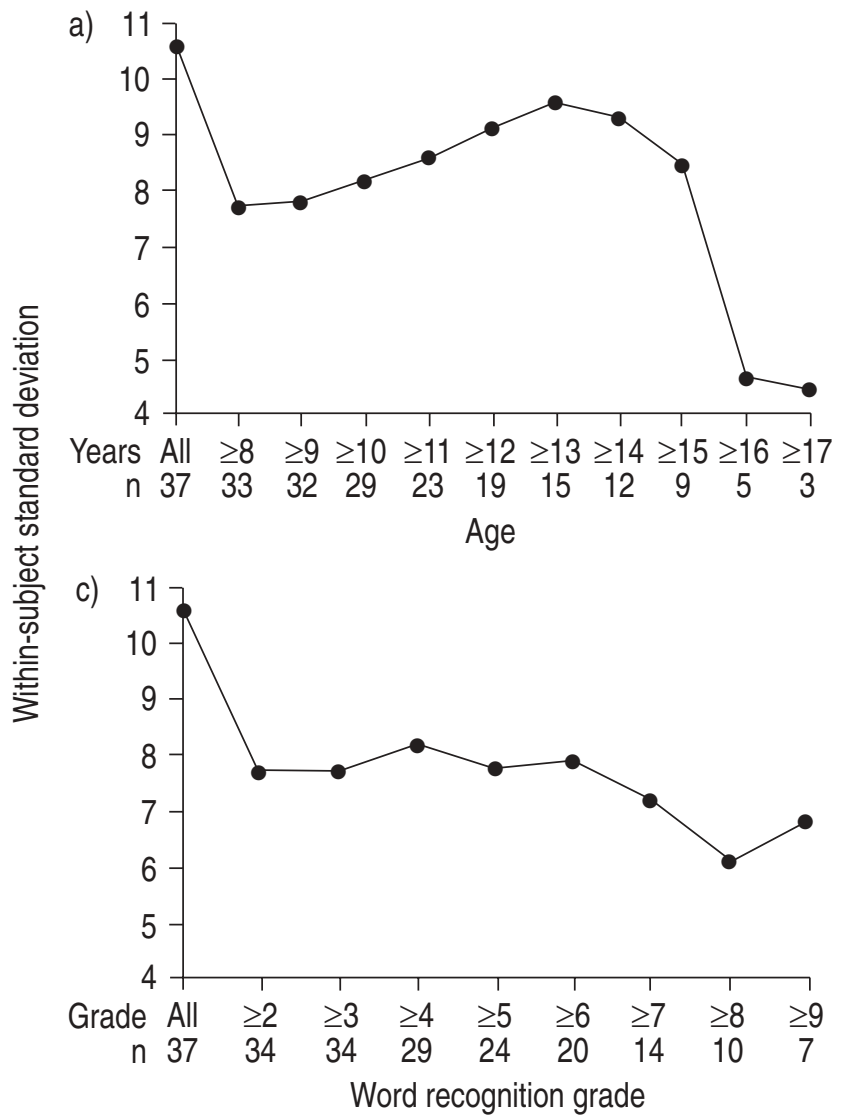

ity in the older and more skilled children provides evidence of accurate responses (table 3 ).

Standard Gamble. Only 29 children in Group A were able to complete the Standard Gamble and provide a score. When all 29 were included in the analysis, the withinsubject standard deviation was 0.15 and the ICC was 0.24 . Figure 2 shows that the within-subject standard

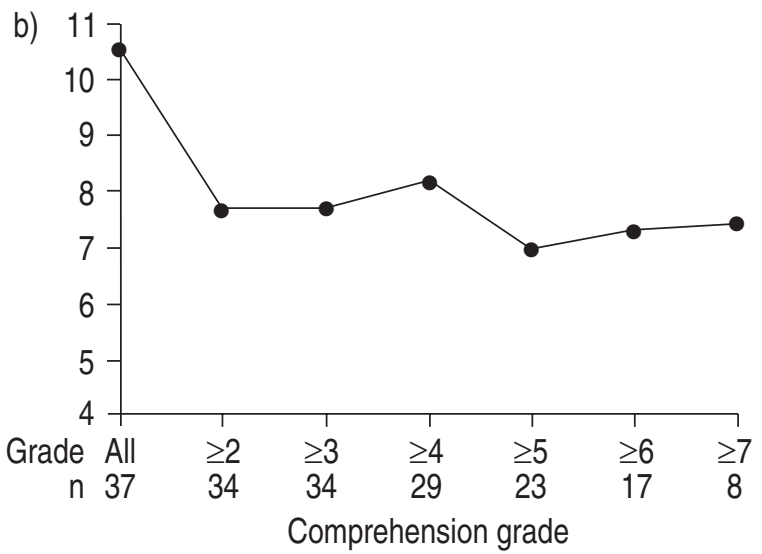

d)

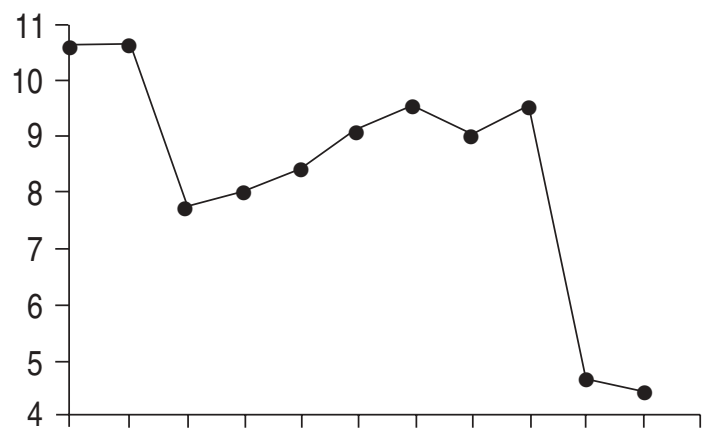

Grade All $\geq 2 \quad \geq 3 \geq 4 \geq 5 \geq 6 \quad 7 \quad \geq 8 \quad \geq 9 \geq 10 \geq 11 \geq 12$

$\begin{array}{lllllllllllll}\text { n } & 37 & 36 & 33 & 30 & 27 & 19 & 15 & 13 & 10 & 5 & 3 & 1\end{array}$

School grade

Fig. 1. - Feeling thermometer: improvement in reproducibility (within-subject standard deviation) with increasing: a) age; b) comprehension; c) word recognition; and d) school grade in patients with stable asthma. n: number of subjects in each group. 
Table 4. - Differences in reliability above and below cut points

\begin{tabular}{|c|c|c|c|}
\hline \multirow[t]{2}{*}{$\begin{array}{l}\text { Predictor } \\
\text { (Cut point) }\end{array}$} & \multicolumn{2}{|c|}{$\begin{array}{l}\text { ICCs below and } \\
\text { above cut-point }\end{array}$} & \multirow{2}{*}{$\begin{array}{l}\text { Ability of the } \\
\text { predictor to } \\
\text { detect dif- } \\
\text { ferences in } \\
\text { reproducibility } \\
\mathrm{p}^{*}\end{array}$} \\
\hline & Below & Above & \\
\hline \multicolumn{4}{|c|}{ Feeling Thermometer } \\
\hline $\begin{array}{l}\text { Age } \\
(<8 \text { vs } \geq 8 \text { yrs })\end{array}$ & $\begin{array}{c}0.25 \\
(n=4)\end{array}$ & $\begin{array}{c}0.71 \\
(\mathrm{n}=33)\end{array}$ & 0.155 \\
\hline $\begin{array}{l}\text { Word recognition } \\
(<2 v s \geq 2)\end{array}$ & $\begin{array}{l}-0.85 \\
(\mathrm{n}=3)\end{array}$ & $\begin{array}{c}0.71 \\
(n=34)\end{array}$ & 0.058 \\
\hline $\begin{array}{l}\text { Comprehension } \\
(<2 \text { vs } \geq 2)\end{array}$ & $\begin{array}{l}-0.85 \\
(\mathrm{n}=3)\end{array}$ & $\begin{array}{c}0.71 \\
(\mathrm{n}=34)\end{array}$ & 0.058 \\
\hline $\begin{array}{l}\text { School grade } \\
(<3 \text { vs } \geq 3)\end{array}$ & $\begin{array}{l}0.25 \\
(\mathrm{n}=4)\end{array}$ & $\begin{array}{c}0.71 \\
(n=33)\end{array}$ & 0.155 \\
\hline \multicolumn{4}{|l|}{ Standard Gamble } \\
\hline $\begin{array}{l}\text { Age } \\
(<12 \text { vs } \geq 12 \text { yrs })\end{array}$ & $\begin{array}{l}-0.06 \\
(\mathrm{n}=11)\end{array}$ & $\begin{array}{c}0.55 \\
(\mathrm{n}=18)\end{array}$ & 0.170 \\
\hline $\begin{array}{l}\text { Word recognition } \\
(<6 \text { vs } \geq 6)\end{array}$ & $\begin{array}{l}-0.05 \\
(\mathrm{n}=10)\end{array}$ & $\begin{array}{c}0.70 \\
19\end{array}$ & 0.018 \\
\hline $\begin{array}{l}\text { Comprehension } \\
(<6 \text { vs } \geq 6)\end{array}$ & $\begin{array}{l}-0.04 \\
(n=13)\end{array}$ & $\begin{array}{c}0.70 \\
(\mathrm{n}=16)\end{array}$ & 0.045 \\
\hline $\begin{array}{l}\text { School grade } \\
(<6 \text { vs } \geq 6)\end{array}$ & $\begin{array}{l}-0.18 \\
(\mathrm{n}=11)\end{array}$ & $\begin{array}{c}0.74 \\
(\mathrm{n}=18)\end{array}$ & 0.033 \\
\hline
\end{tabular}

*: $\mathrm{p}<0.01$ indicates that the predictor was able to differentiate between reliability above and below the cut point (see text). ICC: intraclass correlation coefficient.

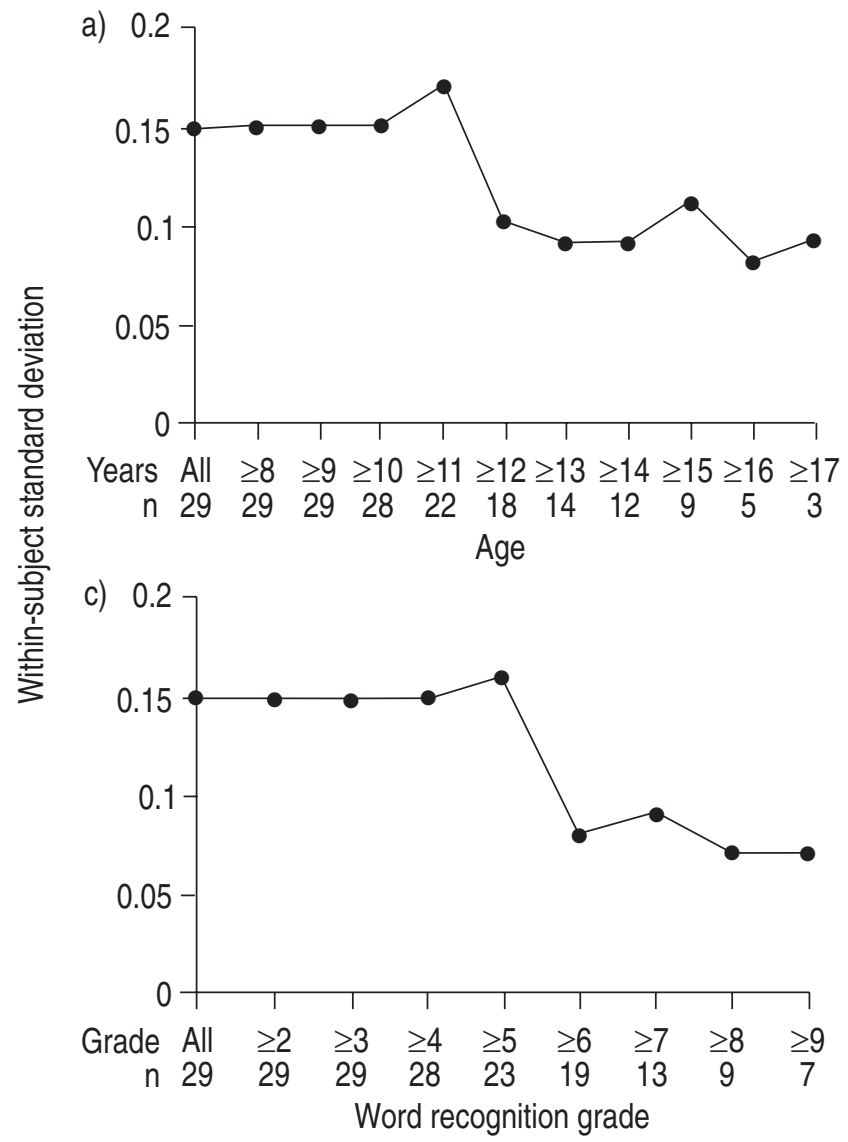

deviation dropped at age 12 yrs, above school grade 6 and above grade 6 reading and comprehension skills. Using these cut-off points resulted in improved reliability (table 4) and, in these children, there was moderately acceptable cross-sectional validity.

\section{Comparison of measurement properties}

The measurement properties of the four instruments have been determined using only reliable data. For the PAQLQ and the HUI, all 52 children were included in the analysis. For the Feeling Thermometer and the Standard Gamble we used only children above the cutoff points shown in table 4 .

Discriminative properties. The reliability of each instrument has been described in detail in the section above.

For cross-sectional construct validity, correlations between each instrument and both clinical asthma measures and other estimates of HRQL are shown in table 3. The PAQLQ and the Feeling Thermometer provided correlations that were moderately close to predicted. For the Standard Gamble, reading skills $\geq$ grade 6 provided correlations that were still acceptably close to predicted, whereas age $\geq 12$ yrs and school grade $\geq 6$ did not. For the HUI, the correlations were not close to predicted for the clinical asthma measures but moderately close to predicted for the HRQL measures.
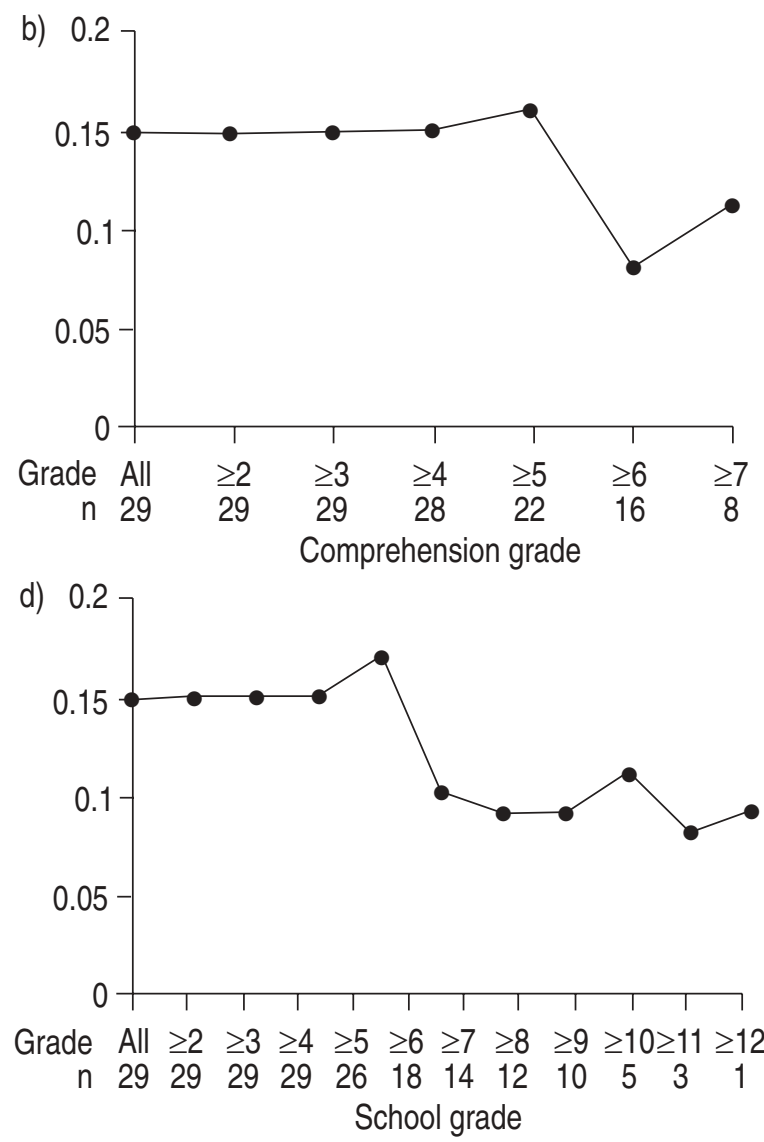

Fig. 2. - Standard Gamble: improvement in reproducibility (within-subject standard deviation) with increasing: a) age; and b) comprehension; c) word recognition; and d) school grade in patients with stable asthma. n: number of subjects in each group. 
Evaluative properties. For the estimation of responsiveness, 32 patients contributed 47 sets of observations to the changed category (Group B), 27 improvements and 20 deteriorations. The PAQLQ and the Feeling Thermometer both showed good responsiveness (table 5).

Table 5. - Responsiveness: the ability of the instrument to detect change

\begin{tabular}{|c|c|c|c|}
\hline Instrument & $\begin{array}{c}\text { Group A } \\
\text { (patients } \\
\text { with stable } \\
\text { asthma) }\end{array}$ & $\begin{array}{c}\text { Group B } \\
\text { (patients in } \\
\text { whom asthma } \\
\text { changed) }\end{array}$ & $\begin{array}{l}\text { Differences } \\
(\mathrm{A} v s \mathrm{~B}) \\
\mathrm{p} \text {-value }\end{array}$ \\
\hline \multicolumn{4}{|l|}{ PAQLQ } \\
\hline Overall & $\begin{array}{c}0.01 \pm 0.25 \\
(\mathrm{n}=57)\end{array}$ & $\begin{array}{c}0.98 \pm 0.88^{\dagger} \\
(\mathrm{n}=47)\end{array}$ & $<0.0001$ \\
\hline Symptoms & $\begin{array}{l}0.03 \pm 0.29 \\
(\mathrm{n}=57)\end{array}$ & $\begin{array}{c}1.03 \pm 0.82^{\dagger} \\
(\mathrm{n}=47)\end{array}$ & $<0.0001$ \\
\hline Activities & $\begin{array}{c}-0.03 \pm 0.60 \\
(\mathrm{n}=57)\end{array}$ & $\begin{array}{c}1.02 \pm 1.32^{\dagger} \\
(\mathrm{n}=47)\end{array}$ & $<0.0001$ \\
\hline Emotions & $\begin{array}{c}0.01 \pm 0.33 \\
(\mathrm{n}=57)\end{array}$ & $\begin{array}{c}0.88 \pm 1.09 \\
(n=47)\end{array}$ & $<0.0001$ \\
\hline HUI & $\begin{array}{l}0.01 \pm 0.05 \\
(\mathrm{n}=57)\end{array}$ & $\begin{array}{l}0.01 \pm 0.05 \\
(\mathrm{n}=45)\end{array}$ & 0.97 \\
\hline \multicolumn{4}{|c|}{ Feeling Thermometer } \\
\hline All patients & $\begin{array}{c}-128 \pm 13.5^{*} \\
(\mathrm{n}=57)\end{array}$ & $\begin{array}{c}11.5 \pm 18.7 * \\
(\mathrm{n}=47)\end{array}$ & 0.0004 \\
\hline Age $\geq 8$ yrs & $\begin{array}{c}-0.76 \pm 10.2 \\
(\mathrm{n}=50)\end{array}$ & $\begin{array}{c}13.8 \pm 15.3^{\dagger} \\
(\mathrm{n}=42)\end{array}$ & $<0.0001$ \\
\hline School grade $\geq 3$ & $\begin{array}{c}-0.76 \pm 10.2 \\
(\mathrm{n}=50)\end{array}$ & $\begin{array}{c}14.7 \pm 15.1^{\dagger} \\
(\mathrm{n}=42)\end{array}$ & $<0.0001$ \\
\hline Word recognition $\geq 2$ & $\begin{array}{c}-0.58 \pm 10.4 \\
(n=52)\end{array}$ & $\begin{array}{c}13.1 \pm 15.3^{\dagger} \\
(n=46)\end{array}$ & $<0.0001$ \\
\hline Comprehension $\geq 2$ & $\begin{array}{c}-0.58 \pm 10.4 \\
(n=52)\end{array}$ & $\begin{array}{l}13.1 \pm 15.3 \\
(\mathrm{n}=46)\end{array}$ & $<0.0001$ \\
\hline \multicolumn{4}{|l|}{ Standard Gamble } \\
\hline All patients & $\begin{array}{c}-0.03 \pm 0.19 \\
(\mathrm{n}=45)\end{array}$ & $\begin{array}{c}0.05 \pm 0.24 \\
(\mathrm{n}=34)\end{array}$ & 0.19 \\
\hline Age $\geq 12$ yrs & $\begin{array}{c}-0.004 \pm 0.13 \\
(n=25)\end{array}$ & $\begin{array}{c}0.08 \pm 0.15^{*} \\
(\mathrm{n}=23)\end{array}$ & 0.04 \\
\hline School Grade $\geq 6$ & $\begin{array}{c}0.02 \pm 0.12 \\
(\mathrm{n}=19)\end{array}$ & $\begin{array}{c}0.09 \pm 0.15^{*} \\
(\mathrm{n}=21)\end{array}$ & 0.08 \\
\hline Word recognition $\geq 6$ & $\begin{array}{c}0.01 \pm 0.12 \\
(\mathrm{n}=19)\end{array}$ & $\begin{array}{c}0.06 \pm 0.12^{*} \\
(\mathrm{n}=21)\end{array}$ & 0.18 \\
\hline Comprehension $\geq 6$ & $\begin{array}{c}0.005 \pm 0.14 \\
(\mathrm{n}=11)\end{array}$ & $\begin{array}{c}0.05 \pm 0.12 \\
(\mathrm{n}=13)\end{array}$ & 0.45 \\
\hline
\end{tabular}

$*: \mathrm{p}<0.05 ; \uparrow: \mathrm{p}<0.0001$, within-subject change (paired t-test). +: unpaired t-test. For further definitions, see table 2.
Both instruments were able to detect changes in the patients whose health status changed (Group B) and to differentiate these patients from those who remained stable (Group A). In children at grade 6 or higher, the Standard Gamble was able to detect improvements in Group B but was unable to differentiate between Groups $\mathrm{A}$ and $\mathrm{B}$. The HUI was unresponsive. For each instrument, we calculated the responsiveness index $(\Delta / \mathrm{SD} \Delta)$ (table 6). The PAQLQ has the highest responsiveness and was significantly more responsive than the HUI. Other differences did not reach significance.

For longitudinal validity, the PAQLQ correlations were closest to predicted with the Feeling Thermometer and the Standard Gamble not quite so close (table 7). For the HUI, correlations were consistently low.

\section{Discussion}

\section{Comprehension}

Our results suggest that children as young as $7 \mathrm{yrs}$ have little difficulty completing the PAQLQ and the high reliability scores in stable patients and good crosssectional validity leaves little doubt that the children were both consistent and accurate in their understanding of the questions and the response options. In this study, the interviewer-administered version was used. Studies currently underway are examining the reading skills required for the self-administered version. Although reliability for the HUI was excellent, cross-sectional validity was poor in all age groups and, therefore, it is impossible to determine, from this study, whether the consistency of responses was accompanied by accuracy of understanding. However, other validation studies suggest that children do understand the questions and tasks accurately $[2,3]$. For the Feeling Thermometer, only the youngest children experienced difficulty and our results for both reliability and validity suggest that there are no problems of comprehension for children with at least grade 2 reading skills. The Standard Gamble is conceptually more difficult and we found that children needed to have a least grade 6 reading skills before one could have confidence in their responses.

Table 6. - Comparison of responsiveness between instruments

\begin{tabular}{|c|c|c|c|c|c|c|}
\hline Instrument & Patients & HUI & $\begin{array}{c}\text { Feeling } \\
\text { Thermometer- } \\
\text { All subjects } \\
(0.48)\end{array}$ & $\begin{array}{c}\text { Feeling } \\
\text { Thermometer- } \\
\text { Comprehension } \geq 2 \\
(0.67)\end{array}$ & $\begin{array}{c}\text { Standard } \\
\text { Gamble- } \\
\text { All subjects } \\
(0.22)\end{array}$ & $\begin{array}{c}\text { Standard } \\
\text { Gamble- } \\
\text { Comprehension } \geq 6 \\
(0.51)\end{array}$ \\
\hline PAQLQ $(0.91)$ & 47 & $* * *$ & $*$ & NS & ** & NS \\
\hline HUI (0.14) & 45 & & NS & $*$ & NS & NS \\
\hline $\begin{array}{l}\text { Feeling Thermometer- } \\
\text { All subjects }(0.48)\end{array}$ & 47 & & & NS & NS & NS \\
\hline $\begin{array}{l}\text { Feeling Thermometer- } \\
\text { Comprehension } \geq 2 \quad(0.67)\end{array}$ & 46 & & & & $*$ & NS \\
\hline $\begin{array}{l}\text { Standard Gamble- } \\
\text { All subjects }(0.22)\end{array}$ & 34 & & & & & NS \\
\hline $\begin{array}{l}\text { Standard Gamble- } \\
\text { Comprehension } \geq 6 \quad(0.51)\end{array}$ & 25 & & & & & \\
\hline
\end{tabular}

The responsiveness index is shown in parentheses after the title of each instrument. 1. Responsiveness index $=\Delta / \Delta \mathrm{SD}$. ${ }^{*}: \mathrm{p}<0.05$; $* *: \mathrm{p}<0.01 ; * * *: \mathrm{p}<0.001$. Ns: nonsignificant. For further definitions see legend to table 2 . 
Table 7. - Longitudinal construct validity ${ }^{+}$

\begin{tabular}{|c|c|c|c|c|c|c|c|c|c|}
\hline \multirow[b]{2}{*}{ Instrument } & \multicolumn{4}{|c|}{ Clinical asthma } & \multicolumn{3}{|c|}{ Quality of life } & \multicolumn{2}{|c|}{ Global ratings } \\
\hline & $\begin{array}{l}\text { Asthma } \\
\text { control } \\
\text { score }\end{array}$ & $\begin{array}{c}\text { FEV1 \% } \\
\text { pred } \\
\text { (Pre-bd) }\end{array}$ & $\begin{array}{l}\text { Peak } \\
\text { flow } \\
\text { rates }\end{array}$ & $\begin{array}{c}\beta \text {-agonist } \\
\text { use }\end{array}$ & $\begin{array}{c}\text { PAQLQ } \\
\text { Overall }\end{array}$ & $\begin{array}{c}\text { PACQLQ } \\
\text { Overall }\end{array}$ & $\begin{array}{c}\text { Impact on } \\
\text { family }\end{array}$ & $\begin{array}{l}\text { Child's } \\
\text { symptoms }\end{array}$ & $\begin{array}{l}\text { Caregiver } \\
\text { re child's } \\
\text { symptoms }\end{array}$ \\
\hline A priori prediction & $0.35-0.50$ & $<0.20$ & $0.20-0.35$ & $0.20-0.35$ & $>0.50$ & $0.20-0.35$ & $0.20-0.35$ & $0.35-0.50$ & $0.20-0.35$ \\
\hline PAQLQ - Overall & 0.27 & 0.09 & 0.40 & 0.40 & N/A & 0.34 & 0.24 & 0.73 & 0.36 \\
\hline HUI & 0.11 & 0.01 & 0.06 & 0.08 & 0.13 & 0.08 & 0.01 & 0.05 & 0.03 \\
\hline Feeling Thermometer & & & & & & & & & \\
\hline All patients & 0.18 & -0.12 & 0.15 & 0.18 & 0.54 & 0.33 & 0.26 & 0.56 & 0.16 \\
\hline Age $\geq 8$ yrs & 0.21 & -0.17 & 0.24 & 0.33 & 0.62 & 0.31 & 0.25 & 0.61 & 0.21 \\
\hline Grade $\geq 3$ & 0.22 & -0.18 & 0.25 & 0.34 & 0.63 & 0.31 & 0.25 & 0.62 & 0.23 \\
\hline Word recognition $\geq 2$ & 0.22 & -0.14 & 0.22 & 0.34 & 0.61 & 0.32 & 0.23 & 0.61 & 0.21 \\
\hline Comprehension $\geq 2$ & 0.22 & -0.14 & 0.22 & 0.34 & 0.61 & 0.32 & 0.23 & 0.61 & 0.21 \\
\hline Standard Gamble & & & & & & & & & \\
\hline Age $\geq 12$ yrs & 0.16 & -0.06 & 0.26 & 0.27 & 0.44 & 0.12 & -0.08 & 0.34 & 0.26 \\
\hline Grade $\geq 6$ & 0.22 & -0.10 & 0.26 & 0.36 & 0.46 & 0.13 & -0.05 & 0.38 & 0.30 \\
\hline Word recognition $\geq 6$ & 0.28 & 0.08 & 0.27 & 0.15 & 0.47 & 0.35 & -0.27 & 0.32 & 0.11 \\
\hline Comprehension $\geq 6$ & 0.19 & 0.05 & 0.14 & 0.04 & 0.29 & 0.27 & -0.37 & 0.14 & 0.19 \\
\hline
\end{tabular}

Values are Pearson correlation coefficients. N/A: not applicable. For definitions, see tables 1, 2 and 3.

For practical purposes, it would be desirable to use a child's age to decide his/her ability to complete an HRQL test. However, as shown in tables 2 and 3, standardized reading tests provide substantially better guidance. In this study, we also looked at school grade. This is certainly better than age but grades in this study come from the Ontario school system where children begin grade 1 in the calendar year of their sixth birthday and occasionally repeat grades on the basis of poor attainment. Therefore, the results may not be applicable outside the province or country.

\section{Instrument measurement properties}

As we have described in detail in a previous publication [4], the PAQLQ has strong discriminative and evaluative properties. The other three instruments varied in their success. When, in the subsequent discussion, we refer to the Feeling Thermometer and the Standard Gamble, we are restricting ourselves to the subpopulations in which instrument reliability was high.

The HUI was highly reliable but completely unresponsive and not valid as either a discriminative or evaluative instrument for asthma-specific HRQL. The high reliability tells us that the instrument is measuring something and data from other studies suggest that it is measuring HRQL [2, 3]. In this study, we excluded children with other illnesses but the high ICC may have stemmed from such impairments as the need to wear glasses. As with any relatively short generic instrument, there is the risk that the questions will not capture the impairments associated with a specific medical condition [15]. In this case, the HUI does not measure paediatric asthma-specific quality of life and investigators should not try to use it for this purpose.

The Feeling Thermometer worked well as both a discriminative and evaluative instrument; it had very good reliability, responsiveness and validity. The Standard Gamble worked less well but still had acceptable measurement properties. When reflecting on the success of the Feeling Thermometer and the Standard Gamble, the reader should remember the way in which the instru- ments were administered. Patients were asked to rate three scenarios presenting mild, moderate and severe asthma and then to think specifically about their asthma when rating their own HRQL. Had they been administered using more generic health state scenarios and the children asked to focus on their health in general, the results might have been quite different. This implies that the HUI, a failure at measuring asthma-specific HRQL, may have been doing a better job of measuring overall HRQL. We did not administer other general HRQL measures that would have allowed us to explore this hypothesis.

A limitation of this study is the relatively small and possibly homogeneous sample. Although we endeavoured to enrol patients to represent a wide range of socioeconomic backgrounds and from both rural and urban settings, most of the children and their parents were Caucasian. In addition, all the children were in the Ontario school system where reading and numeracy skills may be given different emphasis and introduced at different times compared to other provinces and countries. Testing of these instruments in other settings will increase our confidence in the general applicability of the results.

In conclusion, this study has shown that the Paediatric Asthma Quality of Life Questionnaire is quick, easy to understand, and valid for both discriminative (survey) and evaluative (clinical trial/practice) use. It provides information on the different aspects of health-related quality of life that are troublesome to children with asthma (symptoms, emotions and activity limitations) and, very importantly, it is possible to place a clinical interpretation on the data [4]. The Feeling Thermometer is a good algorithm for evaluating the value that children with asthma place on their health status. It is quick to complete and, in children with grade 2 reading skills, it has very good measurement properties. By providing only a single number, clinical understanding of patient's experiences is limited, but a single number on a standardized scale $(0=$ death, $1=$ perfect health) is often a desirable feature for health economists and those responsible for the allocation of healthcare resources. Unlike the Feeling Thermometer, the Standard Gamble meets the assumptions of utility theory and the results can be 
used in cost/utility analyses. However, it is complex, long and difficult to administer, can only be used in children with grade 6 reading skills and has only very modest measurement properties. The Health Utilities Index is quick, easy and reliable, but not valid for measuring asthma-specific quality of life in children.

This suggests that the Paediatric Asthma Quality of Life Questionnaire can be used confidently in clinical trials and clinical practice to provide a profile of a child's experiences, but for specialized studies, such as health care utilization and other pharmacoeconomic studies, the Feeling Thermometer may be more appropriate. The Standard Gamble and Health Utilities Index are unlikely to be of use in children with asthma.

Acknowledgements: The authors thank P. Rosenbaum for his perceptive comments and suggestions during the preparation of the manuscript, A. Willan for statistical support and M. Guldemond and T. Van Beveren for their help and guidance in evaluating reading skills.

\section{References}

1. Guyatt GH, Juniper EF, Feeny DH, Griffith LE. Children and adult perceptions of childhood asthma. Pediatrics 1997; 99: 165-168.

2. Feeny DH, Furlong W, Boyle M, Torrance GW. Multiattribute health status classification systems: health utilities index. Pharmacoeconomics 1995; 7: 490-502.

3. Torrance GW, Furlong W, Feeny DH, Boyle M. Multiattribute preference functions: health utilities index. Pharmacoeconomics 1995; 6: 503-520.

4. Juniper EF, Guyatt GH, Feeny DH, Ferrie PJ, Griffith LE, Townsend M. Measuring quality of life in children with asthma. Qual Life Res 1996; 5: 35-46.
5. French DJ, Christie MJ, Sowden AJ. The reproducibility of the childhood asthma questionnaires: measures of quality of life for children with asthma 4-16 years. Qual Life Res 1994; 3: 215-224

6. Torrance GW. Measurement of health state utilities for economic appraisal: a review. J Health Econ 1986; 5: $1-30$.

7. Brigance $\mathrm{AH}$. Brigance comprehensive inventory of basic skills. Curriculum Associates Inc., North Billerica, Massachusetts. 1993.

8. Juniper EF, Guyatt GH, Feeny DH, Ferrie PJ, Griffith LE, Townsend M. Measuring quality of life in the parents of children with asthma. Qual Life Res 1996; 5: 27-34.

9. Stein REK, Riessman CK. The development of an impacton-family scale: preliminary findings. Med Care 1980; 18: 465-472.

10. Juniper EF, Guyatt GH, Willan A, Griffith LE. Determining a minimal important change in a disease-specific quality of life instrument. J Clin Epidemiol 1994; 47: 81-87.

11. Townsend M, Feeny DH, Guyatt GH, Furlong WJ, Seip AE, Dolovich J. Evaluation of the burden of illness for pediatric asthma patients and their parents. Ann Allergy 1991; 67: 403-408.

12. Guyatt GH, Kirshner B, Jaeschke R. Measuring health status: What are the necessary measurement properties. J Clin Epidemiol 1992; 45: 1341-1345.

13. Guyatt GH, Walter S, Norman G. Measuring change over time: assessing the usefulness of evaluative instruments. J Chron Dis 1987; 40: 171-178.

14. Juniper EF, Guyatt GH, Ferrie PJ, Griffith LE. Measuring quality of life in asthma. Am Rev Respir Dis 1993; 147: 832-838.

15. Rutten-van Molken MPMH, Clusters F, et al. Comparison of performance of four instruments in evaluating the effects of salmeterol on asthma quality of life. Eur Respir J 1995; 8: 888-898. 